\title{
Designing Interactive Technologies for Interpretive Exhibitions: Enabling Teen Participation Through User- Driven Innovation
}

\author{
Vanessa Cesário, Sónia Matos, Marko Radeta and Valentina Nisi \\ Madeira Interactive Technologies Institute, 9020-105, Funchal, Portugal \\ \{vanessa.cesario, sonia.matos, marko.radeta, valentina.nisi\}@m- \\ iti.org
}

\begin{abstract}
The active involvement of teenagers in the design of interactive technologies for museums is lacking further development. Adopting a userdriven innovation framework along with cooperative inquiry, we report and discuss a case study that has been designed to involve users in the ideation of interpretive experiences for a local museum. Working in collaboration with the Natural History Museum of Funchal, this contribution will present and discuss co-design sessions that were aimed at participants with ages 15 to 17 and where they were asked to ideate an interactive museum experience. As a result of the co-design sessions, we have found several design patterns. We have grouped these patterns into four categories that express the interests of a teenage audience; these categories are: "interactions", "gaming", "localization" and "social media". Our findings suggest that teenagers value interactive technologies when visiting museums and that user-driven innovation plays an important role when involving this specific audience in the design of user experiences for museums.
\end{abstract}

Keywords: museums, natural history, mobile interaction, user experience, user research, teenagers, participation, user-driven innovation, cooperative inquiry

\section{Introduction}

With the aim of creating a space for a teenage audience to rethink their local natural museum, in this paper we report on the data as well as the underlying research regarding user-driven innovation. While tackling the visibility of teenage audiences within the field of Human-Computer Interaction (HCI), in this contribution we will also present four design categories that derive from the feedback that we have obtained from a group of teenagers that were involved in a series of co-design sessions. Therefore, the paper will be divided into three sections. Firstly, we discuss the key theoretical challenges that have informed the case-study that underpins this contribution. In this respect, we discuss the lack of participation on behalf of teenage audiences in the design and assessment of interpretive experiences and exhibition strategies of museums. Secondly, we delve into a discussion of how a user-driven innovation framework can be used to involve museum audiences in the process of technological ideation. Finally, and to further complement this discussion, we present 
the findings of a series of co-design sessions where participants were invited to rethink the interpretive exhibition of a local museum.

The discussion of our case-study will be supported with the qualitative data that was obtained from the sessions. A total of 75 students from a local secondary school were initially asked to share their thoughts on their experience regarding the Museum of Natural History of Funchal (in further, MNHF) that is set in Madeira Island, Portugal. They were also invited to ideate a mobile and interactive experience for this venue. The goal of this activity, as explained to the participants, was to design an interactive and mobile user experience to support the MNHF's permanent display of taxidermied marine animals that inhabit the waters that surround the island.

\section{Audience, Participation and the Museum Experience}

To date, museums have reached out to specific audiences in the form of surveys and questionnaires. In order to obtain relevant information and support the design of exhibitions and interpretive experiences, this process has mostly followed a top-down approach [1]. In fact, only few examples demonstrate how museums can actively involve communities in an ideation process that is aimed at improving audience engagement. The Glasgow Open Museum Experiment is often presented as a relevant example. Set in the 1990's, this experiment, amongst others, involved local and mostly marginalized groups in the organization and curation of the museum's exhibitions [1]. Reported by Simon, an impact assessment of Glasgow's Open Museum experiment, conducted in 2002, demonstrated that this project propelled two important contributions. Firstly, the project created "new opportunities for learning and growth" amongst excluded audiences. Secondly, it changed the negative perception of museums amongst marginalized groups.

The Glasgow case study can be given further momentum with the work of Tzibazi [2]. Here, the voices and ideas of a younger audience are problematized. In fact, the author identifies youth as an audience group that is often excluded from a museum's curatorial strategies. This exclusion has a profound impact, this considering that the design of interpretive experiences in museums is no longer sensitive to this group's specific interests and needs, this also limits a museum's potential to create interpretative experiences that have real pedagogical relevance [2]. Drawing on several key studies, Tzibazi also suggests that it is not only museums that ignore a younger audience (ages 13 to 19), members of this group seem to be generally disinterested in what museums can offer. In response to this gap, Tzibazi [2] suggests involving youths through Participatory Action Research (PAR) and as a way of documenting their ideas and interests in relation to museums.

Moreover, Hall and Bannon's [3] study is particularly vested in demonstrating that cooperative design methods have the potential to support the successful introduction of interactive digital technology in museums. According to the authors, in a context where strategies have been mostly focused on the "functionality of [the] technology" (p. 214), the use of cooperative methods opens space for an in-depth understanding of an audience's specific desires and needs. However, apart from Hall and Banon [3], the work of Dindler and colleagues [4] and the work of Ciolfi and colleagues [5], the 
active involvement of specific audiences in the ideation of interactive technologies for museums is lacking further development.

The work reported above, echoes a gap that can be found within the field of HCI more broadly. For example, there are comparatively fewer studies reporting on the active involvement of teenage users. Those that are reported, rarely position teenagers as sources of inspiration and information for design, as for example in the studies reported by Batson and Feinberg [6], Karin Danielsson and Charlotte Wiberg [7]. On the other hand, Katterfeldt et al. [8], suggest that when teenagers are the subject of research, the employed user-centered design methods tend to produce an interpretation of their demands and needs without however leveraging on their direct contribution. Moreover, and set against the benefits that are reported by Hall and Bannon [3], Dindler and colleagues [4], as well Ciolfi and colleagues [5], we argue that it is vital to actively engage teenagers, the next generation of adults, in HCI research. Some authors suggest that teenagers will soon become adults and should therefore be involved in the design of future technologies [9]. As found by Fitton and colleagues [9], they are in a better position to combine both child and adult perspectives. In fact, several methodologies that engage children in the design process have been developed [10]. In this respect, Druin's seminal work on Cooperative Inquiry $[10,11]$ and the Scandinavian approach to Participatory Design [12] have gained acceptance amongst the IDC community. In fact, participatory design is now engaging children $[11,12]$ and teenagers $[7,13-18]$ in the design process. On the other hand, Cooperative Inquiry (CI) is one of the several participatory methods that includes youth in the design process (7-17 years old) $[11,19]$. On this view, in CI, children act as full partners with adults, sharing ideas and evaluating designs [20]. However, and although CI has been used for a long time with children (7-11 years) $[16,20]$, co-design with teenagers (13-17 years) remains less explored [21].

Our attempt to briefly discuss the importance of audience participation, namely the participation of teenagers, to inform the design of user experiences that support interpretive exhibitions in museums, can be understood by returning to the work of Simon [1]. The author had already identified that participatory techniques not only give "voice" to specific audiences, they are also essential in the development of "experiences that are more valuable and compelling". Simon's argument echoes Falk and Dierking's [22] work. Here, the authors contend that "[the] museum represents a community of practice in which myriad communities of learners mingle and learn". Our understanding is that this definition, strengthens the value and importance of audience participation in the ideation of user experiences that are designed to support interpretative exhibitions.

\section{Designing Mobile Experiences for Museums}

In this section, we describe a series of co-design sessions conducted with 75 teenagers, aged 15 to 17 (average age of 16,5) from a secondary school in Funchal. All participating students were enrolled in a multimedia and informatics class. The sessions integrate a broader project that has been developed by the authors and that seeks to introduce interactive technologies in the context of the MNHF. We organized 
20 groups ( 3 to 5 students per group) in 5 sessions over a three-day period. Overall, our sample included 56-male and 19-female students.

We chose a user-driven innovation framework for the group sessions. As it is mostly used by industry [23], we followed this approach to gain a broader understanding of user-driven innovation, one that, "regards users as a source of innovation" [24]. This was set alongside the cooperative inquiry approach that positions participants as "design partners" [11]. Resembling the work of Chang and Kaasinen [25], our choice highlights the importance of adopting user-driven innovation research "methods by which user ideas can be captured and worked on further with designers" (p.66). As both authors argue, in this context, face-to-face focus groups have the power to facilitate participation and to allow HCI researchers to gather information, one that best translates "user's everyday experiences".

Each co-design session was initiated with a presentation of how museums, and our case study, the MNHF, could be enhanced by using interactive technologies. Three questions were used to spark the debate amongst the students. Those questions were:

Q1) What do you think about museums? This question was asked to prompt feedback regarding whether students liked to visit museums and in what situations they usually conduct their visits.

Q2) How do you think interactive technologies could enhance your experience of the museum and how could technology make this visit more enjoyable? This question was important when collecting information regarding the different types of experiences that students would like to explore at the museum.

Q3) Have you ever been to the MNHF and to the museum's aquarium? This final question was used to better understand whether the students enjoyed their experience of the MNHF.

Once the three questions were answered verbally, the MNHF was introduced through a series of photographs that detailed the museum's collection (mammals, geology and reptiles). Subsequently, 13-points of interest relating to the museum's exhibit of taxidermied marine animals were identified on a physical map of the museum. Afterwards, we asked how the young students could think of interaction and user experience for museum settings. Here, techniques from the field of interaction design were explained, such as: (i) research and ideation, (ii) low-fidelity prototypes, (iii) usability feedback, (iv) high fidelity prototypes, followed by (v) development and finally (vi) the user-testing. Our focus was directed toward the design of a mobile application and therefore windows, icons, menus and transitions/gestures were also highlighted as important elements when sketching a mobile app. At the very end, students were asked to think about how several technologies could play a relevant role when visiting the museum. For example, Near Field Communication (NFC), Radio Frequency Identification (RFID), Quick Response Code (QR Code), Augmented Reality (AR), Mobile Virtual Reality (MVR), and Proximity Beacons were provided as a set of examples. These technologies were explained in depth along with examples of their usage.

Finally, our participants were involved in a 30-minute co-design session. Each group was given two sheets (Fig. 1). Sheet A contained three text slots that could be used to explain the experience which they would like to design and portray: 1) Narrative: what is the story of the experience; 2) Species/Artifacts: how do visitors interact with the artifacts; 3) Mechanics/Tutorial: which steps will the user take to 
complete the experience. Sheet B contained an empty wireframe that could be used to draw the interface details for the mobile application that our participants had previously thought.

During the ideation process, we collected notes of the students' interaction and discussing of ideas. As guidance, emphasis was placed on the experiences that they would enjoy in a museum.

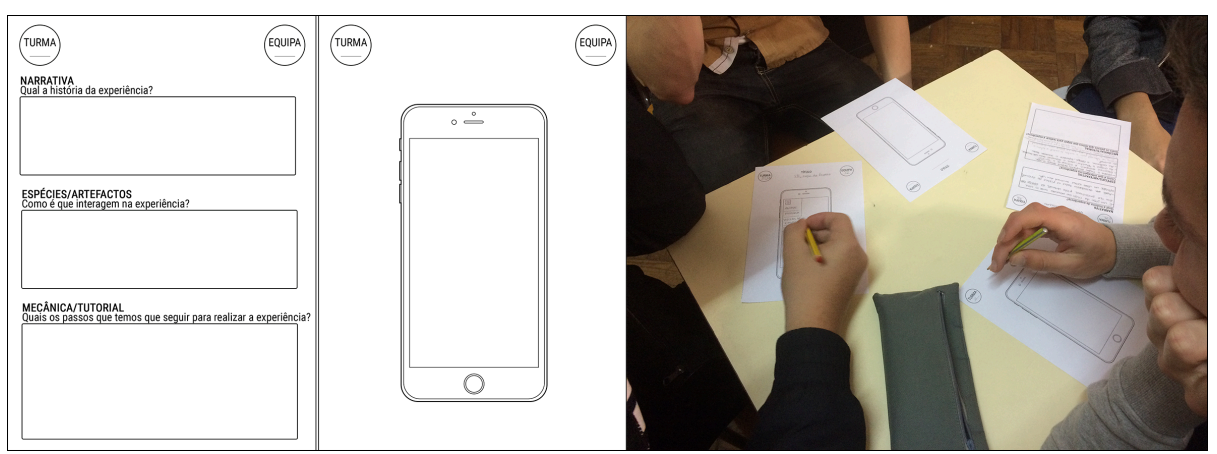

Fig. 1. Sheet A (left), sheet B (center), a group discussing their ideas (right).

\section{Results}

Considering Q1, Q2 and Q3 answers, our young participants considered museum visits a mundane activity. Overall, the students suggested that museums do not offer anything new, which was a reason for avoiding museums all together. Despite this deterring factor, students admitted that they would visit museums during holidays or with their parents. However, when on holiday, our young respondents only visited museums that were located outside of Madeira Island. In fact, only half of the participants visited the MNHF. Most of our participants rated the aquarium as the best feature of the MNHF. Moreover, participants expressed interest towards the integration of videos, digital content and interactions to enhance the museum exhibit. The two most highly rated technologies and interventions were: games (75 participants) and virtual reality (49 participants).

During the co-design sessions, several issues were raised by our participants. Firstly, students advocated for a greater use of interactive technologies in museums, some argued specifically for the importance of play and enjoyment while others suggested a combination of both technology and enjoyment. One group in particular, stressed the value of simplicity and usability to appeal to a wider audience. As our young participants progressed with the co-design sessions, we also took note of some of their spontaneous remarks which highlighted feelings of excitement towards the technological interventions that they were ideating: This is fun!; This is better than Pokemon Go! and For sure I would go to the museum just to try something different like this. 


\subsection{Design categories}

The different groups compiled a total of 20 sets of A and B sheets, which were analyzed in detail and to extract emerging trends and patterns as well as potential insights. The relevant words and phrases that each group wrote on sheet A and drew on sheet B were transcribed and patterns highlighted according to the affinities that emerged from the grouping of words (Fig. 2). We chose to highlight this set of words rather than analyze the ideas that were generated in the co-design sessions because our goal was to generate patterns between the different groups of categories and understand how our participants envisaged compelling museum experiences.

A total of 150-word transcripts were obtained. From these transcripts, four main categories emerged, namely: 1) Interactions, 2) Gaming, 3) Localization, 4) Social media.

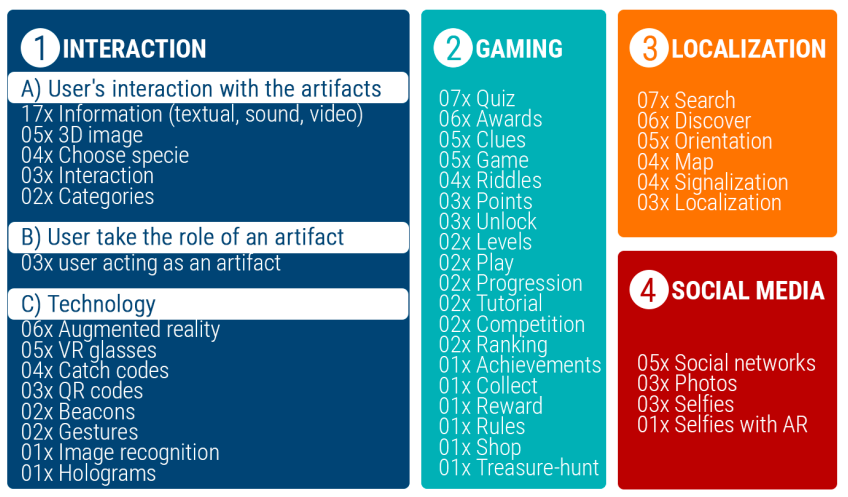

Fig. 2. Word categories gathered from the co-design sessions with teenagers.

Interactions. Words describing interactions and information delivery styles were grouped in the interaction category. This category contained words such as information, choose, codes and can be divided into three subcategories: A) the user interacts with artifacts, B) the user interacts with the museum exhibition while taking on the role of a selected artifact, C) the technology that is used to interact with the exhibit. In the former, the user interacts with the artifacts not only through images and sounds but also by choosing which artifacts they would want to engage with. In this case, the user would choose which artifacts h/she wants to embody. For example, the user could visit the museum through the eyes of a specific marine animal. All the groups used at least one of the above subcategories in their ideas. In this instance, a total of 58 words were transcribed. What we identified as interactions was a complex but popular category, the most important category if we consider the number of words of all the three sub-categories as one.

Gaming. This category emerged from grouping words relating to games and game elements such as achievements, awards and clues. Fifteen groups out of twenty used words and concepts related to the gaming category in their ideas. In this instance, a total of 51 words were transcribed. Gaming was the second choice of preference when designing user experiences in museums. 
Localization. This category was best expressed by a description of user's movements within the museum and could be seen in the discovery of artifacts and in words such as maps, orientation and search. Eleven groups out of twenty used this category in their ideas; a total of 29 words relating to this category were transcribed. Localization was the third most important category amongst the design choices that were made by our participants.

Social media. Finally, the social media category embraced words relating to the usage of photos and social networks within the application, such as selfies, photos, social networks. In this case, seven groups out of twenty used words relating to social media; a total of 12 words were related to the social media category. To our surprise, the social media category was the fourth and last pattern to emerge in terms of popularity, this despite the high consumption of social media by teenagers (see for example the work of Wikia [26]).

\section{Discussion and Concluding Remarks}

Taking into consideration the work of Dindler and colleagues [4] as well as the work of Ciolfi and colleagues [5], in this contribution we have developed and tested a userdriven innovation framework to engage a teenage audience in the design of interactive experiences for museums. Referring back to Simon [1] and Tzibazi [2], we developed co-design sessions with teenagers with ages 15 to 17 . With the aim of engaging young visitors in the ideation of novel user experiences for their local natural history museum (MNHF), we documented their thought processes as well as their interests regarding interactive technology and museums.

Our results led us to agree with Tzibazi [2], from a first glimpse, our young participants showed disinterest in museums. In fact, when we first conducted the codesign sessions, our participants suggested that their local natural history museum did not offer engaging experiences. However, and instead of immediately designing in response to the challenges that were pinpointed by our target audience, we rather harnessed on their potential and ideas as valuable sources of information and inspiration and by engaging them in co-design sessions where they took on the role of "co-creators of museum experiences" [2] and as our "design partners" under the framework of cooperative inquiry [11]. Resembling the work of Chang and Kaasinen [25], our intention was to uncover "user's everyday experiences" and to utilize these experiences when tailoring new design solutions that can capture the attention of those who visit the MHNF, namely the museum's teenage audience. Furthermore, and considering Simon's work [1], the sessions held with our young participants gave them a "voice" and engaged them enthusiastically in the design process. Our study also highlights how much a younger generation values interactive technologies when visiting museums. In fact, it was clear from their answers to our preliminary questions, that they would appreciate the integration of technologically driven playful approaches within the museum and to experience novel and less mundane activities. Participants took close inspiration from the technologies that were demonstrated to them at the beginning of the session (e.g.: NFC, RFID, QR Codes, AR, MVR, 
Beacons). In fact, QR Codes, Beacons, and MVR were mentioned by our participants in the design session and as way of enhancing the museum experience. However, when designing for a mobile experience, participants thought more about the game experience and its mechanics than the technology itself. Moreover, our results resonate with the broader literature which indicates that young people today are born into a world that is flooded by novel technologies. On this view, Wikia [26] reports that the "Generation Z", in this case today's teenagers, are more and more engaged with digital platforms. Besides, further studies argue that when working with this age group, emphasis should be placed on producing combined solutions that connect the use of interactive technologies with more conventional media channels, as seen in Napoli and Ewing [27]. According to Falk [28], the most compelling aspect of these studies is that the one size fits for all experiences does not apply for most museum visitors. As argued by Napoli and Ewing [27], the same can be said for the "net generation" which is quite different from previous generations, particularly when it comes to their beliefs and behaviors.

Following this discussion, the most relevant point that emerged from our study is the need to create a broader range of experiences for the NHMF. Most relevant categories that emerged from the study are 1) the need for different experiences, followed by 2) gaming, 3) location based technologies, and 4) social media. The social media category, which appeared last, was somewhat surprising this given the fact that it is widely appreciated amongst a teenage demographics [13]. We believe that this point would deserve further investigation. The four categories derived from the co-design sessions contribute to the field of HCI more broadly, this considering that they revealed valuable insights which could be considered as guidelines when designing experiences for a teenage audience. Therefore, and based on the categories derived from our study, future work will be aimed at creating and adapting experiences based on these categories to the specificities of the MHNF. This would allow us to understand whether these categories can be applied to the tours that are already in place at the museum and in order to engage and capture the attention of a teenage audience. Furthermore, this paper complements Hall and Bannon's discussion [3], one that argues for the use of cooperative methods when designing for a museum context. Moreover, we argue that a user-driven framework is important when designing for a teenage audience. In fact, our findings verify that the participants were fully engaged in the creation of a mobile experience for a museum context, wanting to try them out in situ. Together, these findings form a roadmap to guide the development and maturation of a mobile museum experience solution that is targeted at teenagers. In fact, we envisage that our findings can inform the design, research and evaluation of interactive technologies in a museum context. We also foresee their application to other localities around the globe.

Acknowledgments. The work reported in this contribution was developed with the support of ARDITI (Ph.D. scholarship, Project Number M14-20-09-5369-FSE000001) and with the support of the University of Edinburgh (CAHSS Knowledge Exchange and Impact grant). Our gratitude also goes to the students and teachers of the Multimedia and Informatics class at Francisco Franco's Secondary School. We would also like to thank the Museum of Natural History of Funchal (MNHF) for their timely support and feedback. 


\section{References}

1. Simon, N.: The Participatory Museum, http://www.participatorymuseum.org/, (2010).

2. Tzibazi, V.: Participatory Action Research with young people in museums. Mus. Manag. Curatorship. 28, 153-171 (2013).

3. Hall, T., Bannon, L.: Co-operative design of children'sinteraction in museums: a case studyin the Hunt Museum. CoDesign. 1, 187-218 (2005).

4. Dindler, C., Iversen, O.S., Smith, R., Veerasawmy, R.: Participatory Design at the Museum: Inquiring into Children's Everyday Engagement in Cultural Heritage. In: Proceedings of the 22Nd Conference of the Computer-Human Interaction Special Interest Group of Australia on Computer-Human Interaction. pp. 72-79. ACM, New York, NY, USA (2010).

5. Ciolfi, L., Petrelli, D.: Walking and designing with cultural heritage volunteers I ACM Interactions. ACM Interactions, XXIII. 46-51 (2016).

6. Batson, L., Feinberg, S.: Game Designs that Enhance Motivation and Learning for Teenagers. Electron. J. Integr. Technol. Educ. 5. 34-43 (2006).

7. Karin Danielsson, Charlotte Wiberg: Participatory design of learning media: Designing educational computer games with and for teenagers. Interact. Technol. Smart Educ. 3, 275291 (2006).

8. Katterfeldt, E.-S., Zeising, A., Schelhowe, H.: Designing Digital Media for Teen-aged Apprentices: A Participatory Approach. In: Proceedings of the 11th International Conference on Interaction Design and Children. pp. 196-199. ACM, New York, NY, USA (2012).

9. Fitton, D., Read, J.C.C., Horton, M.: The Challenge of Working with Teens As Participants in Interaction Design. In: CHI '13 Extended Abstracts on Human Factors in Computing Systems. pp. 205-210. ACM, New York, NY, USA (2013).

10.Druin, A. ed: The Design of Children's Technology. Morgan Kaufmann Publishers Inc., San Francisco, CA, USA (1998).

11.Druin, A.: Cooperative Inquiry: Developing New Technologies for Children with Children. In: Proceedings of the SIGCHI Conference on Human Factors in Computing Systems. pp. 592-599. ACM, New York, NY, USA (1999).

12.Robertson, J., Good, J.: Children's Narrative Development Through Computer Game Authoring. In: Proceedings of the 2004 Conference on Interaction Design and Children: Building a Community. pp. 57-64. ACM, New York, NY, USA (2004).

13.Iversen, O.S., Smith, R.C.: Scandinavian Participatory Design: Dialogic Curation with Teenagers. In: Proceedings of the 11th International Conference on Interaction Design and Children. pp. 106-115. ACM, New York, NY, USA (2012).

14.Bell, B.T., Toth, N., Read, J.C., Horton, M., Fitton, D., Little, L., Beale, R., Guo, Y.: Teenagers Talking About Technologies: Designing Technology to Reduce Teen Energy Use. In: CHI '13 Extended Abstracts on Human Factors in Computing Systems. pp. 14911496. ACM, New York, NY, USA (2013).

15.Isomursu, M., Isomursu, P., Still, K.: Capturing tacit knowledge from young girls. Interact. Comput. 16, 431-449 (2004).

16.DiSalvo, B., Guzdial, M., Meadows, C., Perry, K., McKlin, T., Bruckman, A.: Workifying Games: Successfully Engaging African American Gamers with Computer Science. In: Proceeding of the 44th ACM Technical Symposium on Computer Science Education. pp. 317-322. ACM, New York, NY, USA (2013).

17.Read, J., Fitton, D., Cowan, B., Beale, R., Guo, Y., Horton, M.: Understanding and Designing Cool Technologies for Teenagers. In: CHI '11 Extended Abstracts on Human Factors in Computing Systems. pp. 1567-1572. ACM, New York, NY, USA (2011).

18.Toth, N., Little, L., Read, J.C., Fitton, D., Horton, M.: Understanding teen attitudes towards energy consumption. J. Environ. Psychol. 34, 36-44 (2013). 
19.Druin, A.: The role of children in the design of new technology. Behav. Inf. Technol. 21, 125 (2002).

20.Eladhari, M.P., Mateas, M.: Semi-autonomous Avatars in World of Minds: A Case Study of AI-based Game Design. In: Proceedings of the 2008 International Conference on Advances in Computer Entertainment Technology. pp. 201-208. ACM, New York, NY, USA (2008).

21.Read, J.C.C., Horton, M., Iversen, O., Fitton, D., Little, L.: Methods of Working with Teenagers in Interaction Design. In: CHI '13 Extended Abstracts on Human Factors in Computing Systems. pp. 3243-3246. ACM, New York, NY, USA (2013).

22.Falk, J.H., Dierking, L.D.: Learning from Museums: Visitor Experiences and the Making of Meaning. AltaMira Press (2000).

23.Buur, J., Matthews, B.: Participatory Innovation: A Research Agenda. In: Proceedings of the Tenth Anniversary Conference on Participatory Design 2008. pp. 186-189. Indiana University, Indianapolis, IN, USA (2008).

24.Holmquist, L.E.: User-driven Innovation in the Future Applications Lab. In: CHI '04 Extended Abstracts on Human Factors in Computing Systems. pp. 1091-1092. ACM, New York, NY, USA (2004).

25.Chang, T.-R., Kaasinen, E.: Three User-driven Innovation Methods for Co-creating Cloud Services. In: Proceedings of the 13th IFIP TC 13 International Conference on Humancomputer Interaction - Volume Part IV. pp. 66-83. Springer-Verlag, Berlin, Heidelberg (2011).

26.Wikia: Generation Z: A Look At The Technology And Media Habits Of Today's Teens, http://www.prnewswire.com/news-releases/generation-z-a-look-at-the-technology-andmedia-habits-of-todays-teens-198958011.html.

27.Napoli, J., Ewing, M.T.: The Net Generation. J. Int. Consum. Mark. 13, 21-34 (2000).

28.Falk, J.H.: Identity and the Museum Visitor Experience. Routledge, Walnut Creek, Calif (2009). 